\title{
PUPILS’ PRECONCEPTIONS ABOUT HEAT, TEMPERATURE AND ENERGY
}

\begin{abstract}
This article is focused on finding out pupils' preconceptions about heat, temperature and energy. As a research tool we used a didactic test with individual types of tasks about the concepts. A total of 122 respondents aged 12 to 14 participated in the research. The research sample consisted of two groups of pupils. One group consisted of pupils attending a school assigned for talented pupils, for simplicity they are referred as talented pupils. The second group consisted of pupils who do not attend this type of school, we marked them as "general population". The number of respondents in the sample of talented pupils was 54. The number of respondents in the sample "general population" was 68 pupils. In the research we compared ideas about concepts heat, temperature and energy of talented pupils and pupils of the "general population". We also compared talented pupils and pupils of the "general population" in solving of conceptual and algorithmic tasks in didactic test. We found out pupils of the age from 12 to 14 have misconceptions about the concepts. We also identified the misconceptions and the most common are also mentioned in this article.
\end{abstract}

Keywords: heat, temperature, energy, thermochemistry, preconceptions, misconceptions

\section{Introduction and theoretical background}

In the last few decades natural science education has focused on scientific literacy. In the future, it is expected that thanks to science education students will be able to communicate in the world which is shaped by science and different technologies [1]. Chemistry, which has the key role in science education, is characterized by large rate of abstraction. If we want to describe everything around us (in our environment), we use different kinds of concepts. If we want to describe chemical reaction, we use chemical concepts. It is important that students are able to explain the concepts correctly, understand them and use them in the correct meaning. If they do not, it means students have misconceptions about the concepts. Authors of many researches [2-4] found out students' misconceptions in one of field chemistry - thermochemistry.

One of the reasons why misconceptions exists in this field of chemistry is that thermochemistry is abstractly and conceptually difficult and as authors Holman and Pilling [3] mentioned thermochemistry provides deep knowledge about the functioning of universe.

\footnotetext{
${ }^{1}$ Department of Didactics in Science, Psychology and Pedagogy, Faculty of Natural Sciences, Comenius University in Bratislava, Mlynská dolina, Ilkovičova 6, 84215 Bratislava, Slovak Republic, phone +421260296451

*Corresponding author: kramarova25@uniba.sk
} 
Difficulties of understanding thermochemistry are shown in the research of Castier and Amer [4] in which they found out thermochemistry is not only difficult for students to learn but also for teaching.

Regarding to thermochemistry there exist some researches that were focused to students' understanding of concepts heat, temperature and energy [5-7]. Despite these concepts being considered in physics as elementary, they are very important in understanding to thermochemistry.

In their study Erickson and Tiberghein [7] focused on understanding of the concepts heat and temperature and found out that students think bodies made of different materials have different temperature. In many cases, students regard temperature of body with its size, for example they claimed temperature of big ice cube is lower than temperature of smaller ice cube and that bigger ice cube will melt longer than smaller ice cube. Students also believe bigger bodies contain more heat than smaller bodies. Kircher and Schneider [8] claim that reasons of misconceptions existence about heat are caused by two different everyday life experiences. On the one hand, people discuss the heat's flow from hot bodies to cold bodies: concept heat is used as an expression of energy's direction. On the other hand, people consider the heat measured by thermometer. It means that using of concept heat is related to temperature. We often claim that it is hot outside, but it means there is high temperature outside.

In connection with energy Barke et al. [9] claims that chemical energy and its changes to other forms are very important topic in chemistry, but also very difficult for imagination because we can't observe it directly. Few of us realize that chemical energy ensures functioning of our body system - in our body substances high in energy for instance carbohydrates (starch) change to substances lower in energy - carbon dioxide and water and it leads to warming up of our body. Barke et al. [9] also claims that there is no chance of avoiding misconceptions about energy and receive adequate concept about it. It is caused by using the concept of energy in everyday life situations and by deficiency of accurate mental representations.

For instance conservation and energy change we are not accustomed to connects with everyday life situations such as discharge batteries or fuel consumption despite the fact that they are a base to understand thermochemical reactions. Because of this these concepts are pushed into the background and are not evolved by students.

\section{$\operatorname{Aims}$}

Ideas, which are developed by students in connection with certain concepts without previous knowledge about the concept, are not in some cases absolutely incorrect and we define them like preconceptions. Teachers of nature science oriented subject should know student's preconceptions which can occur within some topic of curriculum. The knowledge about students' preconceptions can also help teachers to avoid introducing the misconceptions to students [9].

Usually, a teacher has a relatively wide diapason of students in his classroom ranging from highly talented to those with fewer prerequisites for studying. If he wants to provide adequate application to all groups of students under these conditions of collective education, he should know their initial concepts. 
As we documented the recency of the issues connected to students' and pupils' misconceptions about concepts heat, temperature and energy in the introduction, we have set the following aims:

- To detect pupils' preconceptions about heat, temperature and energy at two different kinds of schools. One type of school is assigned for talented pupils (their aptitude was verified upon admission to the school by input measurements, which include both pedagogical and psychological diagnostics and they accomplish the generally valid and internationally respected limit of aptitude).

- To compare ideas about concepts heat, temperature and energy of talented pupils and pupils of the "general population".

- To identify preconceptions about thermochemistry and receive a compact view about pupils' understanding thermochemical concepts.

- To find out, if there is a difference between talented pupils and pupils of the "general population" in solving of conceptual and algorithmic tasks in didactic test.

In the context of aims of our research we formulated following research questions:

- What are most common pupils' preconceptions about heat, temperature and energy?

- Is there a difference between how these groups of pupils perceive the concepts?

Our hypothesis in terms of determining the level of appropriation of individual concepts by pupils of different types of schools was:

- Preconceptions of talented pupils will be more extensive and closer to scientific meanings in comparison of pupils of the "general population". Talented pupils will achieve in didactic test aimed to using thermochemical concepts higher average gain point.

\section{Methodological issues}

\section{Characteristics of the research instrument}

As the method for data collection we chose didactic test (research instrument). We created a test, which was based on previous researches with thermochemistry issue so we used tasks, which were already tested. The majority of tasks, which were aimed at detection of pupils' preconceptions about heat, temperature and energy, have been taken from researches realized by authors: Erickson and Tiberghein [7], Lewis and Linn [6] and Kircher and Schneider [8].

Research instrument contains 20 testing tasks and majority of them contains also other tasks (questions). In the test there are 4 open testing tasks with broad answer (tasks number: $1 ; 3 ; 13 ; 14), 5$ open testing tasks with a narrow response (tasks number.: $8 ; 9 ; 10 ; 11 ; 12$ ) and 9 two-level tasks (tasks number: $2 ; 4 ; 5 ; 6 ; 7 ; 15 ; 16 ; 17 ; 18$ ). Total number of testing tasks was 24.

Because one of our aims was to find out pupils' initial concepts about heat, temperature and energy, during the evaluation we divided test items into tasks focused on these concepts. From this point of view, test consists of 4 items focused on heat concept (tasks number: $1 ; 3 ; 12 ; 13$ ), 8 items focused on temperature concept (tasks number: $2 ; 5 ; 6$; $7 ; 8 ; 9 ; 10 ; 11$ ) and 8 items focused on energy concept (tasks number: $4 ; 14 ; 15 ; 16 ; 17 ; 18$; $19 ; 20$ ). Further we divided test items into conceptual (tasks number: $1 ; 2 ; 3 ; 4 ; 6 ; 7 ; 9 ; 10$; $13 ; 14 ; 16 ; 17 ; 18 ; 19 ; 20$ ) and algorithmic (tasks number: $5 ; 8 ; 15 ; 11 ; 12$ ) tasks, but in 
some conceptual tasks memory can have its role as well, if the topic had been introduce to pupils before solving our didactic test.

\section{Evaluation of tasks in didactic test}

For each correct answer pupils could receive maximum of one point. Pupils, whose answer was partially correct, received half of one point. Maximum number of points which pupils could receive in didactic test was 34 points. Time limit for solving the test was 45 minutes.

Examples of selected tasks used in didactic test, accepted correct answer in these tasks and their evaluation

Introduction of all tasks used in didactic test could take up the main part of the article. Because of it, we introduce only some samples of used tasks.

As an example of task focused on concepts heat and temperature, we present the task No. 3. Author of the task is Lewis [6]. Its formulation is:

Task No. 3: In general, are heat energy and temperature the same or different?

Circle one: same / different

a) What is the main reason for their similarity or difference?

b) Give an example that explains your answer.

As correct characteristics of concept temperature we considered answers similar to the next definitions:

- temperature is a quantity, which expresses whether a body is cold or hot in comparison to the standard;

- temperature is a measure of the average kinetic energy of particles (atoms/molecules) of a substance. It is expressed in Celsius degree $\left[{ }^{\circ} \mathrm{C}\right]$, Fahrenheit $[\mathrm{F}]$ or Kelvin $[\mathrm{K}]$ [10].

We also considered it as correct if pupils wrote characteristic of concept heat and gave an explanation the most similar to the following definition and example:

- Definition: heat is a quantity, which describes interaction between systems, or rather the energy transfer process. Thus, the temperature difference between the two systems determines whether heat transfer occurs [7].

- Example: if we heat a certain amount of water through the flame of the burner, the temperature of both the water and the burner flame are different, so there is a certain temperature difference between them. It means that heat is transferred from one system - gas + air to another system - water [7].

For correct answer in task No. 3 pupils could get maximum 2 points.

As an example of task focused on concept energy we present the task No. 17 [10]:

Task No. 17: A swimming pool of water and cupful of water have the same temperature $-100{ }^{\circ} \mathrm{C}$. Choose the correct answer.

a) A total energy of water in the swimming pool is the same as a total energy of water in the cup.

b) A total energy of water in the swimming pool is greater than a total energy of water in the cup.

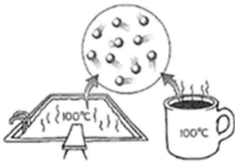

Fig. 1 
c) A total energy of water in the swimming pool is less than a total energy of water in the cup.

d) None of the above.

Explain your answer.

The correct answer is the option b). We considered as the correct following explanation:

- whereas a total energy of water in the swimming pool is greater than a total energy of water in the cup, the average movement of a water molecules is the same in the swimming pool and in the cup. The only difference is in the swimming pool there is much more water molecules than in the cup [10].

If pupils gave the same or a similar explanation, they got 1 point. Maximum points pupils could get in the task No. 17 were 2 points.

As the examples of conceptual tasks we chose the task No. 1 and the task No. 7. Authors of the tasks are Erickson and Tiberghien [7]. The task No. 1 was:

Task No.1: Define the concept of the heat.

As the correct answer we considered the definition most similar to following:

- Heat is defined as an energy that transfers from a hotter body to a colder body.

If pupils' answer was correct, pupil could get maximum 1 point.

The conceptual tasks included also task No. 7:

Task No. 7: In Eric's container there is a little water, and in Stephane's container there is a lot of water. The two camping stoves are set at the same level. The two thermometers are the same.

When the water is boiling in each of the containers, is the temperature read by Eric:

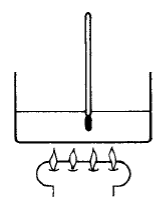

Fig. 2

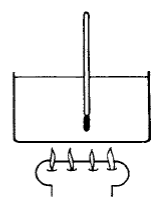

a) higher than the temperature read by Stephane;

b) equal to the temperature read by Stephane;

c) lower than the temperature read by Stephane; or

d) I do not know.

e) What temperature does Eric read?

f) What temperature does Stephane read?

The correct answer in the first part the task is option b). Pupils received 1 point for choosing this option. The correct answer to questions e) and f) is $100{ }^{\circ} \mathrm{C}$. If the answer was in e) and $\mathrm{f})$ the same $\left(100{ }^{\circ} \mathrm{C}\right)$, pupils got 1 point for each. Maximum quantity of points in this part of the task were 2. It means in the task No. 7 pupils could get maximum 3 points.

The conceptual task, solution to which can be affected by memory, an intuitive understanding of the concept in connection with everyday life situations or the occurrence of the concept in other subjects, is task No. 14:

Task No. 14: Define the concept of the energy and give an example.

As the correct answer we consider one closest to the definition given in the book Conceptual chemistry [10]: 
- Energy is the capacity to do work. If something has energy, it can do work on something else - it can exert a force and move that something else. Accordingly, energy is not something we observe directly. Rather, we only witness its effect. As the correct examples we considered examples of energy forms as electric, nuclear, sun energy etc. or changes of energy forms. If pupils gave the correct example, they got 1 point. Maximum number of points in the task No. 14 was 2 points.

\section{Characteristics of the research sample}

A total of 122 respondents aged 12 to 14 participated in the research. The research sample consisted of two groups of pupils. One group consisted of pupils attending a school assigned for talented pupils, for simplicity they are referred as talented pupils. The second group consisted of pupils who do not attend this type of school, we marked them as "general population". The number of respondents in the sample of talented pupils was 54. The number of respondents in the sample "general population" was 68 pupils. It is important to say that none of the samples had previously been presented the concepts heat, temperature and energy, both in the subject of chemistry and in the subject of physics.

\section{Used statistical methods and data analysis tools}

After obtaining the didactic test data it is very important to assess the quality of the individual test tasks. We used the following features to determine the quality of the test tasks:

- $\quad$ task difficulty,

- task sensitivity.

Another characteristic of the research tool we investigated was:

- the reliability of the research instrument (didactic test).

For data analysis we used basic descriptive characteristics of the sample, the dependence between the two variables was determined by Pearson correlation coefficient and the established hypotheses were verified by a parametric test of significance - Student's $t$-test (normal set distribution). The data came from two different groups, so we used an unpaired $t$-test for evaluating. We tested the difference of variance of both data sets by F-test.

\section{Results and discussion}

By calculating the reliability value as Cronbach's alpha, we found that the didactic test is reliable $(r=0.8)$.

Table 1 Comparison of the average number of points in the test and the average success rate of test solution of talented and "general population" pupils

\begin{tabular}{|c|c|c|}
\hline & $\begin{array}{c}\text { The average number of } \\
\text { points in the test }\end{array}$ & $\begin{array}{c}\text { The average success rate of test } \\
\text { solution [\%] }\end{array}$ \\
\hline Talented pupils & 14.23 & 42.0 \\
\hline Pupils of the "general population" & 17.28 & 51.0 \\
\hline
\end{tabular}

The overall success rate of the test for both groups of pupils was $47.0 \%$. The average score of talented pupils was 14.23 points. The success rate of the test in this group of pupils 
was $42.0 \%$. Pupils of the "general population" got an average of 17.28 points in the test. The success rate of the test in this group was $51.0 \%$ (Table 1).

Then, we collected basic data that belong to descriptive statistics and we can use them to describe the data set, namely Skewness and Kurtosis. Comparing the total point gains of talented pupils and pupils of the "general population", the skew coefficient value was 0.33 (left-angled distribution). The value of the Kurtosis was - 0.7 (flat distribution). In both cases the value is close to 0 . So we can conclude that data have a normal data distribution.

In relation to the aims of our research, we detected a difference between achievements of talented pupils and pupils of the "general population" about the concepts of heat, temperature and energy. Comparing the average point gains achieved in the test by talented and "general population" pupils, the $p$-value of the F-test was $0.15(p>0.05)$. That indicates that there is no statistically significant difference between the sample variations (statistically both dispersions are the same). The $p$-value of the Student's $t$-test is 0.0012 . From the results we can conclude that there is a statistically significant difference in the success rate of talented pupils and pupils of the "general population". It means pupils of the "general population" had better results in the test. That is probably due to the fact that the pupils of the "general population" were solving the tasks from a "more practical" point of view. It means that they were able to apply the concepts better to situations of everyday life on which most of the tasks were focused. Statistical processing of data to determine the existence of a difference in the solution of tasks focused on the concepts heat, temperature and energy between talented pupils and pupils of the "general population" is presented in Table 2.

Table 2

The average number of points gained in the test and the statistical processing of the results of talented pupils and pupils of the "general population" in tasks related to the concepts of heat, temperature and energy

\begin{tabular}{|c|c|c|c|c|}
\hline \multirow{2}{*}{} & \multicolumn{2}{|c|}{$\begin{array}{c}\text { The average number of } \\
\text { points }\end{array}$} & \multicolumn{2}{c|}{ The statistical processing of the results } \\
\cline { 2 - 5 } & $\begin{array}{c}\text { Talented } \\
\text { pupils }\end{array}$ & $\begin{array}{c}\text { "General } \\
\text { population" }\end{array}$ & $\boldsymbol{p}$-value F-test & $\boldsymbol{p}$-value $\boldsymbol{t}$-test \\
\hline Tasks - concept heat & 0.16 & 0.41 & 0.13 & 0.08 \\
\hline Tasks - concept temperature & 0.49 & 0.58 & 0.26 & 0.008 \\
\hline Tasks - concept energy & 0.65 & 0.61 & 0.4 & 0.05 \\
\hline
\end{tabular}

The $p$-value of the F-test for all task types indicates that the selections are from a population with the same variance. By calculating Students' $t$-test, we found that there was a statistically significant difference in the solution of tasks focused on the concepts of temperature and energy between talented pupils and pupils of the "general population".

Only in the case of tasks focused on the concept of heat, based on Students' $t$-test ( $p$-value $=0.08)$, we can say that the difference between the tested mean values of talented and "general population" pupils is not statistically significant. It means that the preconceptions of the talented pupils and the pupils of the "general population" do not differ about the concept of heat.

As we mentioned above, the overall success rate of the test was only $47.0 \%$. For this reason we also present solutions of some tasks focusing on the concepts, from quantitative and qualitative points of view. 
To illustrate the solution of tasks focused on the concept of heat, we present scores of both groups of pupils and the success rates of the solution on the example of task No. 1, in which pupils explained in few sentences the concept heat (Table 3).

Table 3

Success in solving the task of the concept of heat in talented pupils and pupils of the "general population"

\begin{tabular}{|c|c|c|c|c|}
\hline \multirow{2}{*}{} & \multicolumn{4}{|c|}{ The success rates } \\
\cline { 2 - 5 } & Talented pupils [\%] & Score & $\begin{array}{c}\text { “General } \\
\text { population” [\%] }\end{array}$ & Score \\
\hline Task No.1 & 19.4 & 10.5 & 61.8 & 42 \\
\hline
\end{tabular}

After analysing the pupils' responses, we can point out following findings:

- pupils of the "general population" were more successful in solution of task No. 1 than talented pupils,

- talented pupils replaced concept heat with the concept temperature, these pupils explained the concept heat in relation to temperature and they mentioned units of temperature and possibilities of measuring it,

- the most frequent answer, in group "general population" pupils, was that heat is an internal energy that expresses how much of its energy the body receives or transfers.

The misconceptions of talented pupils, which replaced the concept heat with the concept temperature are consistent with the findings of research, which realized Kircher and Schneider [8]. They indicated that the reasons of the existence of misconceptions about heat go out from the using of the concept in everyday life. For instance, in relation to weather - outside is hot $=$ outside is high temperature, as we mentioned in the introduction of the article. The answer in this sense provided $16.7 \%$ talented pupils but also $11.8 \%$ pupils of the "general population".

Erickson and Tiberghien [7] pointed out that children like to talk about heat in terms of the body's "hotness" state and tend to associate heat with living organisms or heat sources. Children often say that: "the heat is increasing, connect heat with the sun - the sun is shining and warming the earth, or the heat is spreading from the sun to the air".

Similar concepts were found in $20.4 \%$ of talented pupils and $7.35 \%$ of pupils of the "general population". Examples of the most frequent characteristics of the concept heat of both groups of pupils are given in Table 4 .

The most frequent characteristics of the concept heat of both groups of pupils

Table 4

\begin{tabular}{|c|c|}
\hline The most frequent characteristics of the concept heat & {$[\%]$} \\
\hline A physical quantity that expresses the internal energy that a body receives or transmits & 42.6 \\
\hline A physical quantity & 11.1 \\
\hline Relation to temperature, temperature measurement in [ $\left.{ }^{\circ} \mathrm{C}\right]$ or $[\mathrm{F}]$ & 13.0 \\
\hline $\begin{array}{c}\text { Relation to the heat/temperature of our body, physical activity, feeling of heat when we touch } \\
\text { something hot }\end{array}$ & 8.33 \\
\hline
\end{tabular}

As an example of the solution of the task focused on the concept of temperature, we present the score and the success of the solution of task No. 2 (Table 5), in which pupils had to decide whether objects made from different materials placed in the same room at the 
same time had the same temperature, different temperature or their temperature depends on the material from which they were made. The pupils of the "general population" were in the task No. 2 more successful, but from the results we can conclude that this group of pupils also has misconceptions about the concept of temperature. Overall success of task No. 2, in which pupils chose the answer from the offered options, was $24.0 \%$ and the correct explanation for task No. 2 was reported by only $19.0 \%$ of pupils.

The success in solving the task focused on concept temperature in talented pupils and pupils of the "general population"

\begin{tabular}{|c|c|c|c|c|}
\hline & \multicolumn{3}{|c|}{ The success rates } \\
\cline { 2 - 5 } & $\begin{array}{c}\text { Talented pupils } \\
{[\%]}\end{array}$ & Score & $\begin{array}{c}\text { "General } \\
\text { population" [\%] }\end{array}$ & Score \\
\hline Task No. 2 - Choose correct option & 20.4 & 11 & 26.5 & 18 \\
\hline Task No. 2 - Explanation & 16.7 & 9 & 61.8 & 48 \\
\hline
\end{tabular}

By analysing the pupils' responses, we found out following:

- in both groups of pupils, the most frequent choice from the options was that the one, according to which the objects on the tray have different temperatures and their temperature depends on the material from which they are made,

- $\quad$ in the explanations for selection of the previous option, both groups of pupils referred to different materials of the objects.

Our findings are consistent also with the research realized by Erickson and Tiberghien [7], who found out that pupils think that different material bodies have different temperatures in the same room. Most pupils also believe that metallic objects are cooler than wooden ones, according to this research. The same findings achieved in his research Lewis et al. [6], who also examined pupils' ideas about the concepts of heat and temperature.

To illustrate the solution of tasks focused on the concept of energy, we present the scores and values of solution success achieved in task No. 14, in which pupils had to explain the concept energy in a few sentences.

In both groups of pupils there is the existence of misconceptions about the concept. We also show the achieved scores and the success of solution of the task (Table 6). In relation to the values given in Table 6 we can conclude that talented pupils, as well as pupils of the "general population", were not in the task No. 14 very successful. This is also evidenced by the overall success achieved by pupils in the task $-37.0 \%$.

Table 6

Success in solving the task focused on the concept of energy

\begin{tabular}{|c|c|c|c|c|}
\hline \multirow{2}{*}{} & \multicolumn{3}{|c|}{ The success rates } \\
\cline { 2 - 5 } & $\begin{array}{c}\text { Talented pupils } \\
{[\%]}\end{array}$ & Score & $\begin{array}{c}\text { "General } \\
\text { population" [\%] }\end{array}$ & Score \\
\hline Task No. 14 & 36.1 & 19.5 & 38.2 & 24 \\
\hline
\end{tabular}

Based on a qualitative analysis, we came to the following statements:

- in the explanation of the term energy formed by pupils of "general population", the connection between energy and particle movement predominated $(16.2 \%)$ 
- the second most frequent explanation of the concept of energy formed by pupils of the "general population" coincided with the explanations of talented pupils - energy is the ability to do work ("general population" - $13.2 \%$; talented pupils - $11.1 \%$ ).

The most frequent answers of both groups of pupils in task No. 14, which show the perception of the concept of energy by pupils are in Table 7.

Table 7

The most frequent characteristics of the concept energy of talented pupils and pupils of the "general population"

\begin{tabular}{|c|c|}
\hline The most frequent characteristics of the concept energy & [\%] \\
\hline Relation of energy with movement & 4.92 \\
\hline Relation of energy with force & 7.38 \\
\hline Relation of energy with ability to do work & 8.20 \\
\hline Different forms of energy & 8.20 \\
\hline Movement of atoms and molecules & 9.84 \\
\hline Energy is something that is released by the heat & 4.92 \\
\hline Absence of answer & 43.4 \\
\hline
\end{tabular}

The overall evaluation of the didactic test has shown that pupils naturally have gaps in the understanding of the concepts or tender perceptions of the concepts and misconceptions about the concepts.

Another aim was to find out if talented and "general population" pupils differ in solving of conceptual and algorithmic tasks. Some tasks (for example task No. 1 - Explain the term heat in a few sentences, or task No. 14 - Explain the term energy in a few sentences, and give an example) could be considered as memory tasks if the knowledge of the concepts were presented to pupils before testing. It was not this case so both tasks were classified as conceptual tasks.

The results of the F-test and Students' $t$-test, together with the average number of points obtained in both sets in individual types of tasks (conceptual and algorithmic), are given in Table 8.

Table 8

The average number of points and statistical processing of results by talented pupils and pupils of the "general population" in conceptual and algorithmic tasks

\begin{tabular}{|c|c|c|c|c|}
\hline \multirow{2}{*}{} & \multicolumn{2}{|c|}{ The average number of points } & \multicolumn{2}{c|}{ Statistical processing of results } \\
\cline { 2 - 5 } & Talented pupils & $\begin{array}{c}\text { "General } \\
\text { population" }\end{array}$ & $\boldsymbol{p}$-value F-test & $\boldsymbol{p}$-value $\boldsymbol{t}$-test \\
\hline Conceptual tasks & 0.51 & 0.58 & 0.2 & 0.001 \\
\hline Algorithmic tasks & 0.50 & 0.54 & 0.5 & 0.2 \\
\hline
\end{tabular}

The F-test values in both conceptual and algorithmic tasks showed that there was a statistically insignificant difference between the variance - both sets came from a population with the same variance. The value of the unpaired Students' $t$-test only for conceptual tasks showed that the difference between the tested mean values is statistically significant. Therefore, we reject the null hypothesis of the compliance of the mean values. So we can say that there is a difference in the solution of conceptual tasks between talented and "general population" pupils.

In contrast, the values of Students' $t$-test in the case of solving algorithmic tasks show that talented pupils and pupils of the "general population" do not differ in the solution of 
this type of tasks. We expected that in all types of tasks focused on identifying pupils' preconceptions about the concepts, the difference between talented pupils and pupils of the "general population" will be statistically significant and talented pupils will achieve better results. It is necessary to say that the group of talented pupils consisted of pupils, who visit a school that works with pupils with a general capability, not a capability for natural sciences. Pupils of the "general population" can often be more successful in solving the tasks than talented pupils, because they may be more practical.

Another fact that may have influenced the results of the research is the age difference between talented pupils and the pupils of the "general population". Although the pupils of the "general population" had the subject chemistry for the first year, they were one grade ahead. The difference between pupils is also in the framework program of the schools.

We cannot generalize the results of the research to the entire population because the sample available was small.

In regard to the achieved results we want to draw the attention to the difference between nescience and preconception. Maybe it was nescience, why talented pupils achieved lower scores in the tasks. Talented pupils often prefer different kind of understanding or thinking. From this reason they could choose and form different answers than pupils of the "general population".

\section{Conclusion}

One of our aims was to find preconceptions of pupils about the concepts of heat, temperature and energy in pupils attending two different types of schools (a school for gifted pupils and a school without such a specialization). The results of the didactic test showed that in both groups of pupils aged from 12 to 14, there are misconceptions about the concepts or the absence of some knowledge. It shows also the overall success of the test $47.0 \%$. By analysing of pupils' responses, we have identified the following misconceptions of pupils:

- confusion between the concept heat and temperature,

- correlation of the temperature of the object with the material from which it is made,

- correlation of temperature with size, volume of the body/substance,

- thermal insulators secure the loss of heat of the ice cubes,

- to melt bigger ice cube is needed much more thermal energy than to melt smaller ice cube,

- the total energy in the cup is the same as the total energy in the swimming pool.

Another aim was to compare the preconceptions of the concepts between talented pupils and pupils of the "general population". Our research question was: "Is there a difference in how this group of concepts is perceived by talented pupils and pupils of "general population"? By comparing of the results, which achieved pupils in task focused on the concepts, the $p$-values of F-tests for all types of tasks showed that the samples came from a population with the same variance. Based on Students' $t$-test values, there is a statistically significant difference between talented pupils and pupils of the "general population" only in solving tasks focused on the concepts of temperature and energy. In solving the individual types of tasks were in all cases, more successful pupils of the "general population". 
Our hypothesis that the preconceptions of talented pupils about the concepts will be wider and closer to scientific understanding in comparison to pupils of the "general population" has not been confirmed.

The aim of the research was also to find out if there is a difference in the solution of conceptual and algorithmic tasks between the groups of pupils. By comparing the results achieved by talented pupils and pupils of the "general population" in conceptual and algorithmic tasks, we can claim that groups of pupils differ only in the success of solving conceptual tasks. In solving of the conceptual tasks were again more successful the pupils of the "general population".

The obtained results could be, as we mentioned above, caused by the fact that in most cases the pupils of the "general population" are more practical in real life and also that these pupils, despite the fact that they had subject chemistry for the first year, were one grade ahead. The available selection of talented pupils did not consist primary of pupils talented primarily in science. This fact could also influence the results of the research.

The available sample was small we cannot generalize the results of the research to the entire population in a given age category. The results of the didactic test have shown that there are misconceptions about the concepts of heat, temperature and energy in the research sample. Based on that we want to focus on the didactic reconstruction of the topic thermochemistry and then give the pupils the same test. We want to design learning model of the topic, in which we use constructivism. Traditional teaching models are generally ineffective. One of the ways how alternative concepts can be reduced is to use teaching models that can adapt initial ideas to cognitive conflict strategies to change understanding. One of this model is for instance Elicit-Predict-Confront-Observe-Explain-Reinforce (EPCOER) model [11], Rule Space Model (RSM) [12] and also problem based learning $[13,14]$. Active involvement of students in the teaching process is one of the ways how to enhance teaching of thermochemistry [15]. Subsequently, we will focus on comparison of the overall success of the test results as well as comparison of the success of talented pupils and pupils of the "general population", either in tasks focused on the concepts of heat, temperature and energy, or in conceptual and algorithmic tasks. We will find out if our actions have a different impact on talented pupils and pupils of the "general population". We assume that in this case the differences between talented pupils and pupils of the "general population" will be statistically more significant.

However, it will be important to assess if our designed learning model is effective or not. In this case, we will also work with the control sample, which will be thought the traditional way.

\section{Acknowledgements}

This research was realized with a support of the following grant project: Comenius University Grants for Young Scientists, registration number: UK/346/2020

\section{References}

[1] Neumann K, Viering T, Boone WJ, Fischer HE. Towards a learning progression of energy. J Res Sci Teach. 2013;50(2):162-88. DOI: 10.1002/tea.21061.

[2] Baran M, Sozbilir M. An application of context-and problem-based learning (C-PBL) into teaching thermodynamics. Res Sci Educ. 2018;48(4):663-89. DOI: 10.1007/s11165-016-9583-1.

[3] Holman J, Pilling G. Thermodynamics in context: A case study of contextualized teaching for undergraduates. J Chem Educ. 2004;81(3):373. DOI: 10.1021/ed081p373. 
[4] Castier M, Amer MM. XSEOS: An evolving tool for teaching chemical engineering thermodynamics. Educ Chem Eng. 2011;6(2):e62-70. DOI: 10.1016/j.ece.2010.12.002.

[5] Barker V. Beyond Appearances: Students' Misconceptions about Basic Chemical Ideas. A report prepared for the Royal Society of Chemistry; 2000. DOI: 10.1.1.649.3454.

[6] Lewis EL, Linn MC. Heat energy and temperature concepts of adolescents, adults, and experts: Implications for curricular improvements. J Res Sci Teach. 1994;31(6):657-77. DOI: 10.1002/tea.3660310607.

[7] Erickson G, Tiberghien A. Heat and Temperature. Children's Ideas in Science. Philadelphia: Open University Press; 1985. ISBN: 0335150403.

[8] Kircher E, Schneider W, editors. Physics Didactics in Practice. Berlin: Springer-Verlag; 2013. ISBN: 3540419373.

[9] Barke HD, Hazari A, Yitbarek S. Misconceptions in chemistry: Addressing perceptions in chemical education. Berlin: Springer-Verlag; 2009. ISBN: 978354070988-6.

[10] Suchocki JA. Conceptual Chemistry. 5th ed. London: Pearson Education; 2014. ISBN: 9780321804419.

[11] Enggarani B, Ibnu S, Santoso A. Elicit-Predict-Confront-Observe-Explain-Reinforce (EPCOER) learning on thermochemistry to reduce alternative concept among students with different initial knowledge. JPS. 2019;7(3). DOI: 10.17977/jps.v7i3.12520.

[12] Chen F, Zhang S, Guo Y, Xin T. Applying the rule space model to develop a learning progression for thermochemistry. Res Sci Educ. 2016; 47(6):1357-78. DOI: 10.1007/s11165-016-9553-7.

[13] Montero E, Alaoui FEM, González-Fernández MJ, Aguilar F. Teaching thermodynamics to electronic engineers through active teaching strategies. EDUCON. IEE. 2012. DOI: 10.1109/EDUCON.2012.6201071.

[14] Etiubon RU, Ugwu AN. Problem-based learning and students' academic achievement on thermodynamics: A case study of University of Uyo. IOSR-JRME. 2016;6(5):36-41.

[15] Ceylan T. Challenges of engineering thermodynamics education. Proc 2012 ASEE Annual Conf. 2012. Available from: http://ilin.asee.org/Conference2012/Papers/Ceylan.pdf. 